\title{
IN VITRO INHIBITORY ACTIVITY OF CELL-FREE SUPERNATANTS OF LACTOBACILLUS SPP. AND BACILLUS SPP. AGAINST FUSARIUM GRAMINEARUM
}

\author{
Harčárová, M. ${ }^{1}$, Čonková, E. ${ }^{2}$, Nad, P. $^{1}$, Váczi, P. ${ }^{2}$, Proškovcová, M. ${ }^{2}$ \\ ${ }^{1}$ Department of Animal Nutrition and Husbandry \\ ${ }^{2}$ Department of Pharmacology and Toxicology \\ University of Veterinary Medicine and Pharmacy in Košice \\ Komenského 73, 04181 Košice \\ Slovakia
}

michaela.harcarova@ulvf.sk

\section{ABSTRACT}

In this study, the antifungal activity of cell-free supernatant (CFS) of Lactobacillus spp. (Lactobacillus plantarum CCM 1904; L81, Lactobacillus fermentum; 2I3, Lactobacilus reuteri; 2/6, L26;) and Bacillus spp. (Bacillus subtilis CCM 2794, Bacillus licheniformis CCM 2206) against two strains of Fusarium graminearum CCM F-683 and Fusarium graminearum CCM 8244 were investigated in vitro. All tested CFS of Lactobacillus spp. were able to inhibit the growth of both strains of Fusarium graminearum. The highest inhibitory effect (IE) (56.5\%) against F. graminearum CCM F-683 was observed for CFS Lactobacillus fermentum (2I3) at the minimum inhibitory concentration (MIC) $(2.25 \pm$ $\left.0.56 \mathrm{mg} \cdot \mathrm{ml}^{-1}\right)$. CFS of Lactobacillus reuteri (2/6) showed the best IE (40.0\%) against F. graminearum CCM 8244 (2/6) at the MIC $1.25 \mathrm{mg} \cdot \mathrm{ml}^{-1}$. However, no inhibitory effect of Bacillus subtilis and Bacillus licheniformis CFS against both strains of $F$. graminearum were observed, even at the highest tested concentration of $5.0 \mathrm{mg} \cdot \mathrm{ml}^{-1}$.
Key words: Bacillus spp.; biological protection; inhibitory effect; Lactobacillus spp.; microscopic filamentous fungi

\section{INTRODUCTION}

Fusarium graminearum is one of the most important fungal pathogens of cereal grains (Fig. 1). It is the causal agent of Fusarium head blight (FHB) in wheat and barley [15]. FHB or scab is a plant disease of economically significant importance worldwide [9]. F. graminearum causes direct damage, poor quality of grains and losses of crop and contamination of the raw grains and processed wheat products with mycotoxins [25].

The most important mycotoxin produced by Fusarium graminearum is deoxynivalenol (DON, vomitoxin) and its acetylated derivatives. The presence of deoxynivalenol, in a host-pathogen interaction, can be a virulence factor in Fusarium graminearum wheat infection [21]. In addition, deoxynivalenol and other Fusarium secondary metabolites 


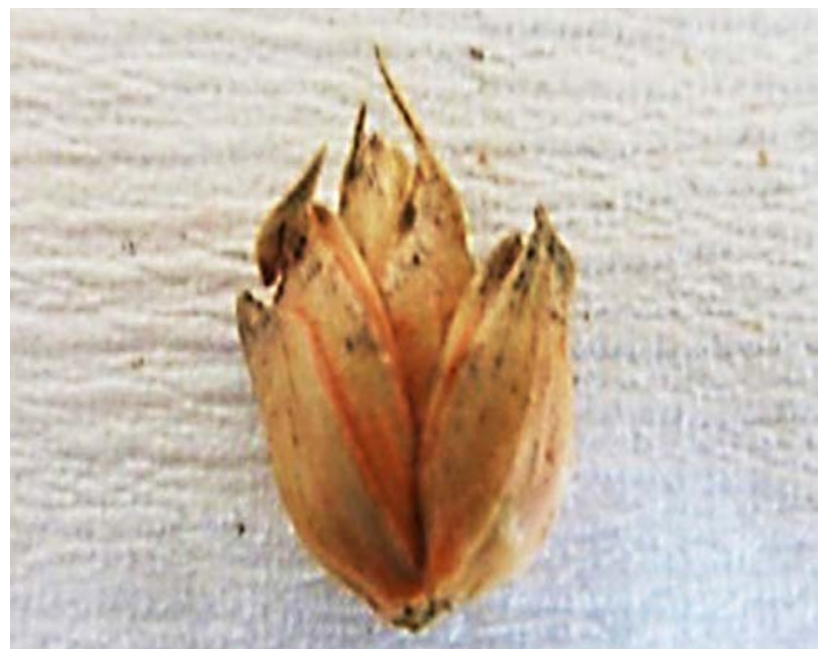

Fig. 1. Sporulation of Fusarium graminearum, which is manifested by orange colouration (own figure)

(zearalenone, fumonisins and other) are very toxic compounds for animals and humans and can cause the socalled mycotoxicosis [17]. Mycotoxicosis are manifested as a variety of clinical signs that depend on factors such as: type and concentrations of mycotoxins; duration of exposure; species; genus; age and health status of the individual [11].

Nowadays, there are various options to eliminate the growth of Fusarium graminearum. In addition to chemical antifungals, adsorbents, antioxidants and biologically active substances are used [22]. According to K o k k o n e n [12], lactic acid bacteria are involved in the biological adsorption of mycotoxins and prevent their absorption from the digestive tract into the blood of humans and animals. The ability of the genus Lactobacillus to suppress the growth of Fusarium microscopic filamentous fungi has been reported [5]. Bacterial endophytes, Bacillus subtilis and $\mathrm{Ba}$ cillus licheniformis are biological tools to protect plants from phytopathogens. They can enter and colonize plants without causing any signs of plant disease. Endophytes penetrate plants from the soil and roots and subsequently spread into leaves, flowers and fruits [2]. Bacillus spp. can protect plant hosts by producing many antimicrobials molecules and induced systemic resistance [23]. The strains of the genus Lactobacillus and Bacillus can be used for the formulation of cell-free supernatants (CFS). CFS are mixtures derived from broth cultures. The separation and removal of cells can be performed using several physical and mechanical processes. CFS can be obtained through two main operations, centrifugation and filtration, or in combination with other technologies according to the desired final product $[3,19]$. Many studies of CFS deal with their utilization in medical and food sectors. The studies on the biostimulant and biocontrol properties of CFS in plants are limited to in vitro tests [19].

The aim of this study was to determine the inhibitory effect of CFS of various species of the genera Lactobacillus and Bacillus subtilis and Bacillus licheniformis.

\section{MATERIALS AND METHODS}

\section{Tested strains}

In the experiment, 9 strains of microorganisms ( Table 1) were used. The strains of F. graminearum CCM F-683, F. graminearum CCM 8244, Lactobacillus plantarum CCM 1904, Bacillus subtilis CCM 2794 and Bacillus licheniformis CCM 2206 were obtained from the Czech Collection of Microorganisms (Masaryk University, Brno, Czech Republic). Other strains of the genus Lactobacillus were provided by the Department of Microbiology and Immunology of the University of Veterinary Medicine and Pharmacy in Košice.

Table 1. The tested strains

\begin{tabular}{lc}
\hline \multicolumn{1}{c}{ Species } & Number \\
\hline & \\
Fusarium graminearum & CCM F-683 \\
Fusarium graminearum & CCM 8244 \\
& \\
\hline & \\
Bacillus subtilis & CCM 2794 \\
Bacillus licheniformis & CCM 2206 \\
& \\
\hline Lactobacillus plantarum & CCM 1904 \\
Lactobacillus fermentum & 213 \\
Lactobacillus plantarum & L 81 \\
Lactobacillus reuteri & $2 / 6$ \\
Lactobacillus reuteri & L26 \\
\hline
\end{tabular}

\section{Preparation of fungal inoculum}

The inoculum suspension was prepared from 10-day old culture of F. graminearum (CCM F-683 and CCM 8244) grown on potato dextrose agar (PDA, HiMedia Laboratories Pvt. Ltd., Mumbai, India). Twenty $\mathrm{ml}$ of physiological saline containing $0.1 \%$ Tween 80 was applied on 
the culture surface and a microbiological stick was used to release conidia from the mycelium. The conidia were then collected with a Pasteur pipette. The density of the fungal inoculum was adjusted to McFarland $2\left(10^{6} \mathrm{CFU} \cdot \mathrm{ml}^{-1}\right)$ by adding saline and using a densitometer (Pliva-LaChema a.s., Brno, Czech Republic). The prepared inoculum was diluted with potato dextrose broth (PDB) to a concentration $10^{6}$ CFU.ml ${ }^{-1}$, which was used for the microdilution testing.

\section{Preparation of cell-free supernatants (CFS) from Lactobacillus spp. and Bacillus spp.}

To prepare CFS from Bacillus subtilis (Bs) and Bacillus licheniformis (B1) strains a 24-hour old culture grown on $\mathrm{B} 10$ agar at $35^{\circ} \mathrm{C}$ was used. Using a sterile inoculation loop (mesh volume $10 \mu \mathrm{l}$ ), bacteria colonies were picked up, and $50 \mathrm{ml}$ of B10 broth, in an Erlenmeyer flask was inoculated. The cell-free supernatant from individual Lactobacillus strains was prepared by inoculating $50 \mathrm{ml}$ of MRS broth with colonies of cells grown under anaerobic conditions on MRS agar at $35^{\circ} \mathrm{C}$ for $48 \mathrm{~h}$, using a Gas pack system. Multiplication of Lactobacillus spp. and Bacillus spp. was performed in a thermostat under aerobic conditions, at $35^{\circ} \mathrm{C}$, by shaking the Erlenmeyer flasks on a horizontal shaker (Orbital Shaker-Biosan) at $170 \mathrm{rpm}$. To obtain CFS, the suspensions formed by Bacillus subtilis (Bs) and Bacillus licheniformis (B1) were centrifuged twice for 20 minutes at $6000 \mathrm{rpm}$, after 24 hours of incubation. Pure, filtered (Q-Max syringe filter, pore size $22 \mu \mathrm{m}$ ) CFS was used to test F. graminearum growth inhibition. Lactobacilli supernatants: Lb. fermentum 2I3 (L1), Lb. reuteri L26 (L3), Lb. plantarum L81 (L4), Lb. reuteri 2/6 (L5) and Lb. plantarum CCM 1904 (L6) were prepared in the same manner, after 48 hour of incubation.

\section{Test procedure}

The microdilution method was used to determine the inhibitory effect of cell-free supernatants. The experiment was performed in 96-well sterile microplates (U shaped), and PDB was used as the medium. Undiluted (100\%) sterile CFS $(200 \mu \mathrm{l})$ was added into the well No. 1 and, subsequently, a series of two-fold dilutions was applied to wells No. 2-10. After application of the fungal inoculum $(100 \mu \mathrm{l})$ to each dilution of CFS, the final concentrations ranged from 5 to $0.01 \mathrm{mg} \cdot \mathrm{ml}^{-1}$. Each Fusarium strain was tested in five rows $(\mathrm{A}-\mathrm{E})$. Row $\mathrm{H}$, which served as a neg- ative control, contained only individual concentrations of CFS $(100 \mu \mathrm{l})$ diluted in PDB $(100 \mu \mathrm{l})$. Column 11 was used as a blank containing $200 \mu \mathrm{l}$ of PDB. Column 12, a positive control, contained $100 \mu \mathrm{l}$ of PDB and $100 \mu \mathrm{l}$ of inoculum. The microtitre plates were incubated for $72 \mathrm{~h}$ at $25 \pm 2{ }^{\circ} \mathrm{C}$, in the dark [6]. After 48-hours of incubation, $15 \mu \mathrm{l}$ of $0.1 \%$ resazurin solution was added into rows $\mathrm{A}-\mathrm{E}$ and $\mathrm{H}$ [13]. The inhibitory effect was determined by measuring the absorbance of the content of wells at $635 \mathrm{~nm}$ using an ELISA reader (Dynex Technologies, Inc., Virginia, USA) and calculated according to the formula:

$$
\begin{aligned}
& \text { IE }(\%)=\frac{(P C-N C)-(S-N C)}{(P C-N C)} \times 100 \\
& \text { IE-the inhibitory effect, } \\
& \text { PC-the absorbance of the positive control, } \\
& \text { NC-the absorbance of the negative control, } \\
& \text { S- the absorbance of the sample. }
\end{aligned}
$$

The lowest concentration of the tested CFS that completely inhibited the growth of Fusarium graminearum mycelium was considered the minimum inhibitory concentration (MIC).

\section{Statistical analysis}

The statistical functions of the MS Excel software were used to evaluate the MIC results and the data obtained in this study were reported as means \pm standard deviations (SD).

\section{RESULTS}

\section{Evaluation of the inhibitory effect of cell-free supernatants}

Table 2 shows the results of the evaluation of MICs and the inhibitory effect of CFS strains of Lactobacillus spp.: L. fermentum 2I3 (L1), L. reuteri L26 (L3), L. plantarum L81 (L4), L. reuteri 2/6 (L5), L. plantarum CCM 1904 (L6) and Bacillus spp.: Bacillus subtilis CCM 2794 (Bs) and Bacillus licheniformis CCM 2206 (B1).

The best inhibitory effect against both Fusarium strains was observed at a concentration of $1.25 \mathrm{mg} \cdot \mathrm{ml}^{-1}$, in CFS L3 (10.8 \% and 7.9 \%, respectively), L4 (5.4\% and $12.3 \%$ ), L5 (6.1\% and $40.0 \%)$ and L6 (8.4\% and $12.5 \%)$. CFS L1 was effective on F. graminearum CCM F-683 at MIC 
Table 2. MICs ( $\mathrm{mg}^{\mathrm{ml}} \mathrm{l}^{-1}$ ) and the inhibitory effect (\%) of cell-free supernatants of Lactobacillus spp. and Bacillus spp. against F. graminearum strains

\begin{tabular}{ccccc}
\hline \multirow{2}{*}{$\begin{array}{c}\text { Tested } \\
\text { strains }\end{array}$} & \multicolumn{2}{c}{ F. graminearum CCM F-683 } & \multicolumn{1}{c}{ F. graminearum CCM 8244 } \\
\cline { 2 - 4 } & $\begin{array}{c}\mathbf{X} \pm \text { SD } \\
{\left[\mathrm{mg}_{\left.\mathrm{m} \mathrm{m}^{-1}\right]}\right.}\end{array}$ & IE & $\begin{array}{c}\mathbf{X} \pm \text { SD } \\
{\left[\mathrm{mg}^{-1} \mathrm{ml}^{-1}\right]}\end{array}$ & IE \\
\hline L1 & $2.25 \pm 0.56$ & 56.5 & $2.5 \pm 0$ & 39.1 \\
L3 & $1.25 \pm 0$ & 10.8 & $1.25 \pm 0$ & 7.9 \\
L4 & $1.25 \pm 0$ & 5.4 & $1.25 \pm 0$ & 12.3 \\
L5 & $1.25 \pm 0$ & 6.1 & $1.25 \pm 0$ & 40.0 \\
L6 & $1.25 \pm 0$ & 8.4 & $1.25 \pm 0$ & 12.5 \\
Bs & $\geq 5.0 \pm 0$ & 0 & $\geq 5.0 \pm 0$ & 0 \\
B1 & $\geq 5.0 \pm 0$ & 0 & $\geq 5.0 \pm 0$ & 0 \\
\hline
\end{tabular}

x-mean values of MIC; SD—standard deviation; IE (\%)—inhibitory effect; L1—L. fermentum 213; L3 - L. reuteri L26; L4—L. plantarum L81; L5-L. reuteri 2/6; L6—L. plantarum CCM 1904; Bs-Bacillus subtilis CCM 2794; Bl—Bacillus licheniformis CCM 2206

$2.25 \pm 0.56 \mathrm{mg} \cdot \mathrm{ml}^{-1}$ and on F. graminearum CCM 8244, at MIC 2.5 mg. $\mathrm{ml}^{-1}$, with inhibitory effect $56.5 \%$ and $39.1 \%$, respectively. CFS from Bacillus subtilis and Bacillus licheniformis did not show a sufficient inhibitory effect even at the highest tested concentration of $5.0 \mathrm{mg} \cdot \mathrm{ml}^{-1}$.

\section{DISCUSSION}

The use of beneficial microorganisms in agricultural, is an increasingly and successful strategy aimed at the elimination of plant pathogens. Biological control by microorganisms is related to the restriction of the use of chemical in agriculture [1, 4]. Many species of Lactobacillus have antifungal activity against microscopic filamentous fungi. Lactobacilli species, L. acidophilus, L. brevis, L.casei, L. fermentum, L. plantarum, L. reuteri, L. rhamnosus and L. sakei are often described as producers of antifungal compounds [14]. The antifungal activity of individual strains of the genus Lactobacillus is associated with the synthesis of organic acids, fatty acids, esters of fatty acids, hydrogen peroxide, bacteriocins and other secondary metabolites [20]. Antifungal activity of CFS probably depends of the overproduction of substances with antifungal effects (low molecular weight and thermally stable substances, bacteriocins) [7]. However, their antifungal activity is usually poor or moderate [14]. In our experiments, CFS from Lactobacillus fermentum at MIC $2.25 \pm 0.56 \mathrm{mg} \cdot \mathrm{ml}^{-1}$ was the most effective against F. graminearum CCM F-683 (56.5\%) and CFS from Lactobacillus reuteri at MIC $1.25 \mathrm{mg} \cdot \mathrm{ml}^{-1}$ against F. graminearum CCM 8244 (40.0\%). Several literature sources point to antifungal efficacy of Lactobacillus and Bacillus bacteria, which produce substances capable of inhibiting the growth of microscopic filamentous fungi Fusarium [8, 10]. Bacillus subtilis and Bacillus licheniformis can enhance growth of the plant and biomass production through synthesis of various phytohormones, fixation of nitrogen, solubilisation of phosphate and production of ammonium ion. Large number of metabolites of these endophytes activate plant and protect them against harmful bacteria and fungi [24]. The antifungal properties of the Bacillus subtilis are mainly attributed to the lipopeptides (fengycin, surfactin and mycosubtilin), which are produced by various strains of this species [16]. In our study, we did not observe an inhibitory effect of CFS from Bacillus subtilis even at the highest tested concentration of $5 \mathrm{mg} \cdot \mathrm{ml}^{-1}$ against F. graminearum. According to Mihalache etal., [16] the combination of lipopeptides from B. subtilis showed potent inhibitory activity at concentrations as low as $5 \mu \mathrm{g} \cdot \mathrm{ml}^{-1}$ against the phytopathogenic fungi F. oxysporum. This antifungal activity is related to the inhibition of spore germination and the irreversible damage of the hyphae cell wall. However, the results of antagonism test showed that the strain Bacillus licheniformis could reduce and inhibit the mycelium growth of various plant pathogens in vitro and in vivo [18]. 


\section{CONCLUSIONS}

Cell-free supernatants of non-pathogenic microorganisms, such as strains of Lactobacillus spp. and soil microorganisms Bacillus subtilis and Bacillus licheniformis deserve a special attention in the future as fungicides. The obtained partial results point to the possibility of their practical application in agricultural practice, as well as to the further direction of scientific research. The use of these bacterial strains creates a space for the study of the synergistic effect of their mutual combinations, possible with other products of natural origin.

\section{ACKNOWLEDGEMENT}

The study was supported by the scientific grant agency, project VEGA No. 1/0402/20 "Effect of additives in the nutrition of monogastric animals on production health, production parameters, products quality and environment".

\section{REFERENCES}

1. Ciancio, A., Pieterse, C. M., Mercado-Blanco, J., 2016: Editorial: Harnessing useful rhizosphere microorganisms for pathogen and pest biocontrol. Front. Microbiol., 7, 1620. DOI: 10.3389/fmicb.2016.01620.

2. Compant, S., Mitter, B., Colli-Mull, J. G., Gangl, H., Sessitsch, A., 2011: Endophytes of grapevine flowers, berries, and seeds: identification of cultivable bacteria, comparison with other plant parts, and visualization of niches of colonization. Microb. Ecol., 62, 188-197. DOI: 10.1007/s00248011-9883-y.

3. Doran, P. M., 2013: Unit operations. Bioprocess Engineering Principles. Elsevier: Amsterdam, The Netherlands, 445-595.

4. Gaiero, J. R., McCall, C., Thompson, K., Day, N. J., Best, A. S., Dunfield, K. E., 2013: Inside the root microbiome: bacterial root endophytes and plant growth promotion. Am. J. Bot., 100, 1738-1750. DOI: 10.3732/ajb.1200572.

5. Gomah, N. H., Zohri, A. N. A, 2014: Inhibition of fungal growth and Fusarium toxins by selected cultures of lactic acid bacteria. J. Microbial. Biochem. Technol. S., 7, 1948-5948. DOI: 10.4172/1948-5948.S7-001.

6. Hadacek, F., Greger, H., 2000: Testing of antifungal natural products: methodologies, comparability of results and assay choice. Phytochem. Anal., 11, 137-147. DOI: 10.1002/(SICI) 1099-1565(200005/06)11:3<137::AID-PCA514>3.0.CO;2-I.

7. Hudáček, J., Zalán, Z., Chumchalová, J., Halász, A., 2007: Antifungal effect of lactobacilli on Fusarium and Aspergillus moulds. Chem. Listy (Chemical Letters), 101, 730-737.

8. Husain, A., et al., 2017: Antifungal activity of lactic acid bacteria isolated from soil rhizosphere on Fusarium species infected chilli seeds. Am. Sci. Res. J. Eng. Technol. Sci., 29, $182-202$

9. Chen, Y., Corby Kistler, H., Zhonghua, M., 2019: Fusarium graminearum trichothecene mycotoxins: Biosynthesis, regulation, and management. Annu. Rev. Phytopathol., 57, 15-39. DOI: 10.1146/annurev-phyto-082718-100318.

10. Khan, N., et al., 2018: Antifungal activity of Bacillus species against Fusarium and analysis of the potential mechanisms used in biocontrol. Front. Microbiol., 9, 2363. DOI: 10.3389/ fmicb.2018.02363.

11. Khatoon, A., ul Abidin, Z., 2018: Mycotoxicosis-diagnosis, prevention and control: past practices and future perspectives. Toxin Rev., 39, 99-114.

12. Kokkonen, M., 2010: Biodegradation of mycotoxins. Food Microbiol., 2, 17.

13. Kumar, P., Mishra, S., Kumar, A., 2016: Antifungal efficacy of plant essential oils against stored grain fungi of Fusarium spp. J. Food Sci. Tech., 53, 3725-3734. DOI: 10.1007/s13197016-2347-0

14. Lipińska, L., Klewicki, R., Klewicka, E., Kołodziejczyk, K., Sójka, M., Nowak, A., 2016: Antifungal activity of Lactobacillus spp. bacteria in the presence of xylitol and galactosyl-xylitol. BioMed Res. Int., 1-8. DOI: 10.1155/2016/5897486.

15. Miedaner, T., Bolduan, C., Melchinger, A. E., 2010: Aggressiveness and mycotoxin production of eight isolates each of Fusarium graminearum and Fusarium verticillioides for ear rot on susceptible and resistant early maize inbred lines. Eur. J. Plant. Pathol., 127, 113-123. DOI: 10.1007/s10658-009-9576-2.

16. Mihalache, G., Balaes, T., Gostin, I., et al., 2018: Lipopeptides produced by Bacillus subtilis as new biocontrol products against fusariosis in ornamental plants. Environ. Sci. Pollut. Res., 25, 29784-29793. DOI: 10.1007/s11356-017-9162-7.

17. Moretti, A., Panzarini, G., Somma, S., Campagna, C., Ravaglia, S., Logrieco, A. F., Solfrizzo, M., 2014: Systemic growth of F. graminearum in wheat plants and related accumulation of deoxynivalenol. Toxins, 6, 1308-1324. DOI: 10. 3390/toxins6041308.

18. Nigris, S., Baldan, E., Tondello, A. et al., 2018: Biocontrol traits of Bacillus licheniformis GL174, a culturable endophyte 
of Vitis vinifera cv. Glera. BMC Microbiol., 18, 133. DOI: 10. 1186/s12866-018-1306-5.

19. Pellegrini, M., Pagnani, G., Bernardi, M., Mattedi, A., Spera, D. M., Gallo, M. D., 2020: Cell-free supernatants of plant growth-promoting bacteria: A review of their use as biostimulant and microbial biocontrol agents in sustainable agriculture. Sustainability, 12, 9917. DOI: 10.3390/su12239917.

20. Perczak, A., et al., 2018: The efficiency of lactic acid bacteria against pathogenic fungi and mycotoxins. Arch. Ind. Hyg. Toxicol., 69, 32-45. DOI: 10.2478/aiht-2018-69-3051.

21. Ponts, N., 2015: Mycotoxins are a component of Fusarium graminearum stress-response system. Front. Microbiol., 6, 1-5. DOI: 10.3389/fmicb.2015.01234.

22. Rashidi, N., Khatibjoo, A., Taherpour, K., Akbari-Gharaei, M., Shirzadi, H., 2020: Effects of licorice extract, probiotic, toxin binder and poultry litter biochar on performance, immune function, blood indices and liver histopathology of broilers exposed to aflatoxin-B1. Poult. Sci., 99, 5896-5906. DOI: 10.1016/j.psj.2020.08.034.
23. Ryan, R. P., Germaine, K., Franks, A., Ryan, D. J., Dowling, D. N., 2008: Bacterial endophytes: recent developments and applications. FEMS Microbiol. Lett., 278, 1-9. DOI: 10.1111/ j.1574-6968.2007.00918.x.

24. Verhagen, B. W. M., Trotel-Aziz, P., Jeandet, P., Baillieul, F., Aziz, A., 2011: Improved resistance against Botrytis cinerea by grapevine-associated bacteria that induce a prime oxidative burst and phytoalexin production. Phytopathol., 101, 768-777. DOI: 10.1094/PHYTO-09-10-0242.

25. Xu, X. M., Nicholson, P., 2009: Community ecology of fungal pathogens causing wheat head blight. Annu. Rev. Phytopathol., 47, 83-103. DOI: 10.1146/annurev-phyto-080508081737.

Received June 12, 2021

Accepted July 19, 2021 